\title{
Management Structure of Product Design of Small and Medium Industries in Thailand to the International Market Education
}

\author{
Supornrat Wongdusitburi ${ }^{1}$ \\ ${ }^{1}$ Faculty of Management, Rajabhat Rajanagarindra University, Thailand \\ Correspondence: Supornrat Wongdusitburi, Faculty of Management, Rajabhat Rajanagarindra University, Thailand. \\ Received: September 4, 2021 \\ Accepted: October 26, 2021 \\ Online Published: November 2, 2021 \\ doi:10.5430/ijhe.v11n2p152 \\ URL: https://doi.org/10.5430/ijhe.v11n2p152
}

\begin{abstract}
The purpose of this research were 1) to synthesize the structure of product design management of small and medium industries in Thailand to the international market education, and 2) to verify the consistency of the relationship between marketing demand and corporate strategy, research and development, innovation and technology and design goals. This research is quantitative and qualitative research. The sample group for quantitative research was 500 small and medium business entrepreneurs, 9 key informants divided into 4 groups: business people, government organization group, academic group, and designer data analysis uses a structured analysis. The analysis of the developed structural models was found that the evaluation criteria were consistent with the empirical data. The relative chi-squared probability was 0.306 , the relative chi-squared probability was 1.042 , the consistency index was 0.957 , and the mean square of the estimation of the error was 0.009 .
\end{abstract}

Keywords: structure, management, product design, small and medium industry

\section{Introduction}

Small and Medium Enterprise (SMEs) is an important engine that plays a role in driving the country's economy. Because it is a production group that has a lot and also widely distributes income to employment Covering a large group of businesses in manufacturing, trade, and service, which currently has a total of 3.04 million, with a growth rate of $1.30 \%$ compared to 2017 accounting for $99.78 \%$ of the total number of enterprises in the country. To play an important role in driving the country's economy. It contributes to 12.15 million people, accounting for 82.22 percent of the country's total employment. It is also a mechanism for driving large industries as SMEs can produce parts and components for various industries, with Thailand that accounts for $99 \%$ of SMEs in the entire country, but these SMEs can create products. The gross domestic product (GDP) is only 42.40 percent of the gross domestic product (Figure 1) (Office of Small and Medium Enterprises Promotion, 2019: 4-01 - 4-05). 


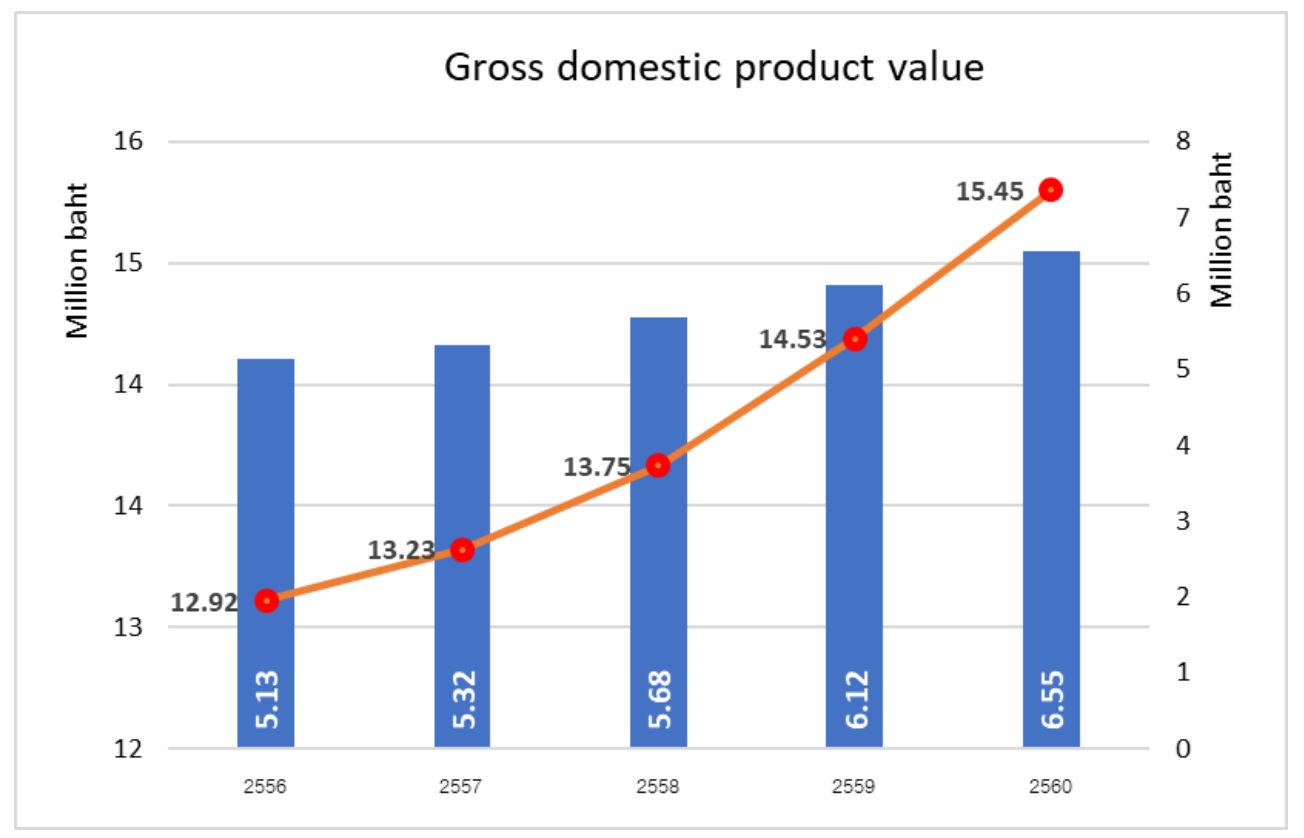

Figure 1. Gross domestic product value in 2013 - 2017

Source: Office of Small and Medium Enterprises Promotion (2019: 1-2)

Most of the problems for Thai SMEs are "Lack of creativity", with most business owners starting their and businesses with their knowledge or expertise. Without market analysis, no advertising, and lack of product and packaging design in building the image and credibility of the product. As a result, the products can not meet the needs and satisfaction of customers (Kotler and Armstrong, 2013). More than $80 \%$ have a production model for contracting or subcontracting to foreign famous manufacturers (Original Equipment Manufacturer: OEM) under the trademark. Including the design and materials used that have already been specified entrepreneurs in Thailand do not see the importance of product design. (National Institute of Development Administration, 2554: 177), in which at present, there are more than 50,000 OEM manufacturing industries in Thailand (Alverson, 2001). No need to invest in product research and design Including brand design Reduce the risk of finding the market yourself. As well as there is no risk from funding to improve the product design process.

However, increasing of business competition due to the advancement of technology resulting in changes in the economic and social system. Each country aims to build the foundation of the well-being of its people through industrial development. The competition situation has become more intense during in the disruptive world. Employers are likely to move their manufacturing outsourcing to a lower-cost source to reduce costs and allow businesses to survive and increase profits. Therefore, from this violent competition Entrepreneurs for the production of general products should change the business direction from being a contractor developed into production with their design (Original Design Manufacturer: ODM), which will help the products stand out from the competition and strengthening the business as well as increasing the potential of future competitiveness in general business products (Sripaiphan, 2010).

Nowadays entrepreneurs need to adapt to stay in the market. Yes, that will not have to deal with the situation Need to adjust to be on par with competitors and compete with technology. No need to have stock able to approach customers all over the world. More streamlined than offline, it may cause problems with operators in the future. If any SMEs have not adapted, it may be too late. If SMEs have an offline store Need to have an additional online system. While people do it online themselves need to have a storefront to fill it up as well. (Office of Small and Medium Enterprises Promotion, 2019)

Therefore, to seek adaptation to the prospect of business survival. we need to accelerate the development of industrial potential. From product design to technology improvement and development (Gilbert, 2014), which Thailand still has a disadvantage in design as a result of not. The importance of design research and development. The introduction of various innovations and technologies in the production process. For this reason, the researcher realized the importance of product design in the SMEs business. Management structure form, product design of 
small and medium industries in Thailand to the international market education. The significance of this research is to serve as a guideline for organizational design management to achieve stability and sustainability in business operations. It is also able to apply the knowledge gained from research to guide SMEs entrepreneurs to develop their products to be competitive.

\section{Method}

Inductive research using combined research. Mixed-methodology research consists of qualitative research in conjunction with quantitative research as follows.

\subsection{Qualitative Research}

The research was conducted through an in-depth interview. The population used in the research was nationally recognized expert by setting expert eligibility criteria. Experts consisted of 9 people, consisting of 4 groups of experts, namely, a group of businessmen, 2 persons, a group of government organizations, 2 persons, a group of academics, and a group of 3 designers. The researcher created an in-depth interview. To collect qualitative data using interviewing according to the intended objectives.

\subsection{Quantitative Research}

The research population was 3,046,793 small and medium business entrepreneurs (Office of Small and Medium Enterprises Promotion, 2019: 4-10) divided into 5 groups: manufacturing, trade, service sector. For the most appropriate level of structural analysis research, 500 samples were determined. Comrey and Lee (1992: 662) used a multi-sampling method. Multistage sampling is obtained a good representative sample. The research instruments were questionnaires that were in a rating scale by specifying 5-level weighting criteria according to the Likert method (Tanin, 2017: 77). The data were used in both descriptive statistics, referenced statistics by SPSS package, and multiple statistical analysis. Multivariate statistical analysis is used for the development of Structural Equations Modeling (SEM) using the AMOS package with the Evaluating the Data-Model Fit criteria to be considered. 4 values (Arbuckle, 2011: 107-109), which are (1) Chi-square Probability Level> 0.05, (2) Relative Chi-square <2 (3) Goodness of fit Index $>0.90$ and (4) Root Mean Square Error of Approximation. $<0.08$.

\subsection{Conceptual Framework}

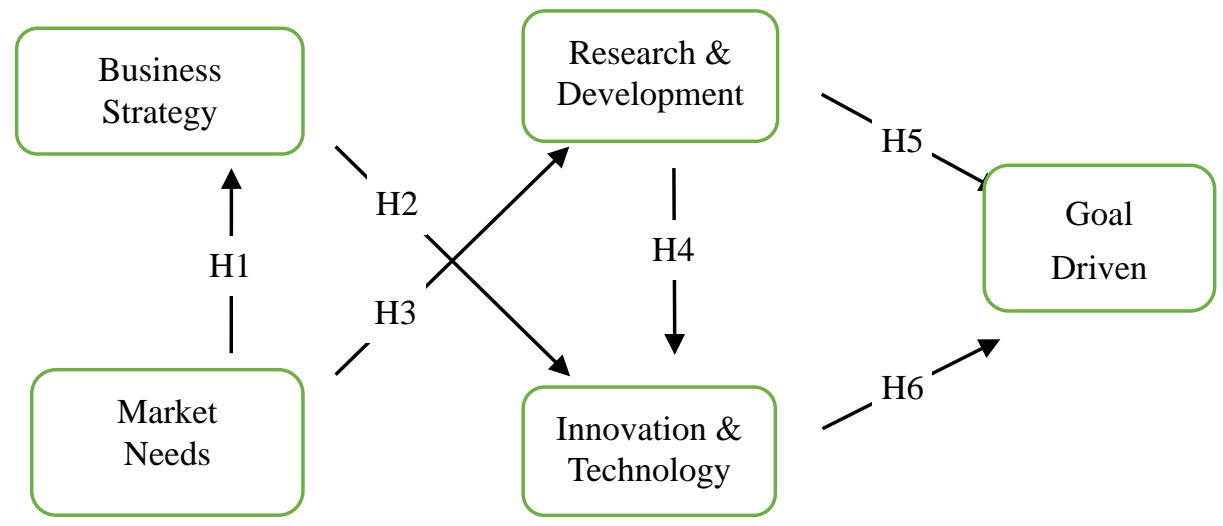

Figure 2. Conceptual framework

\subsection{Research Hypothesis}

H1: Market needs directly influence the potential strategy of the organization.

$\mathrm{H} 2$ : Market needs directly influence latent variables of research and development

H3: Business strategy has a direct impact on innovation \& technology.

H4: Research and development latent influence on innovation \& technology latent variable

H5: Research and development latent influence on goal-driven design latency

H6: Innovation and technology direct influence on goal-driven design latency

\section{Results}

The results of the synthesis of the product design management structure of small and medium industries in Thailand to the international market were found that assessing the consistency of the product design management structure of 
the small and medium industry in Thailand to the International market.

It was found that the relative Chi-square; Chi-square; CMIN / DF) was 2.807, the Chi-Square Probability Level; p) was 0.000. The consistency (Goodness of fit Index; GFI) was 0.596 and the root means a square error of the estimation of tolerance (Root Mean Square Error of Approximation; RMSEA) was 0.053, the model evaluation criteria were not met.

Therefore, the researcher has carried out a structural adjustment. Based on the modification indices as recommended by Arbuckle (Arbuckle, 2011: 107-109), after the improvement of the model, it was found that the Chi-Square Probability Level was 0.306, Relative Chi-square was 1.042, Goodness of fit index was 0.957, and Root Mean Square Error of Approximation is 0.009 , passed the assessment criteria of the model which is consistent with the empirical data as shown in Figure 3, Table 1 and 2.

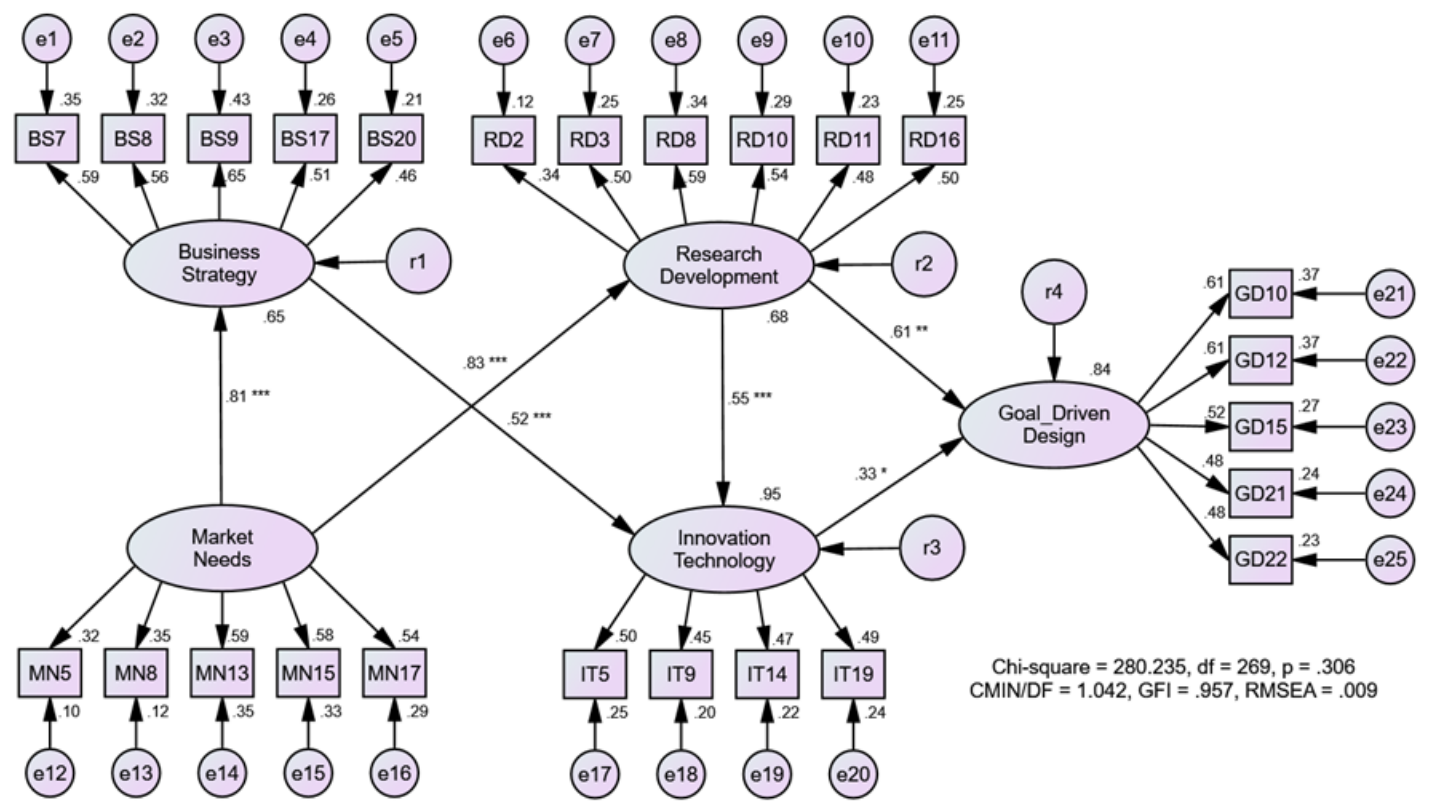

Figure 3. Structure of product design management for small and medium industries in Thailand to the international market education

Table 1. Statistical values of latent variables after structural adjustment

\begin{tabular}{lllllll}
\hline Variable & $\begin{array}{l}\text { Estimate } \\
\text { Standard }\end{array}$ & Unstandard & $\mathrm{R}^{2}$ & variance & C.R. & $\mathrm{P}$ \\
\hline Market Needs & & & & & & \\
$\quad$ Business Strategy & 0.81 & 1.17 & 0.65 & 0.60 & 5.69 & $* * *$ \\
$\quad \begin{array}{l}\text { Research\& Development } \\
\text { Business Strategy }\end{array}$ & 0.83 & 0.61 & 0.68 & 0.01 & 4.76 & $* * *$ \\
$\quad$ Innovation \& Technology & 0.52 & 0.49 & 0.95 & 0.01 & 4.92 & $* * *$ \\
$\quad \begin{array}{l}\text { Research \& Development } \\
\quad \text { Innovation \& Technology }\end{array}$ & 0.55 & 1.00 & 0.95 & 0.01 & 4.40 & $* * *$ \\
$\quad$ Goal Driven Design & 0.61 & 1.40 & 0.84 & 0.04 & 3.26 & $* *$ \\
Innovation \& Technology & & & & & & \\
$\quad$ Goal Driven Design & 0.33 & 0.41 & 0.84 & 0.04 & 2.05 & $*$ \\
\hline
\end{tabular}

* Statistically significant at level $0.05, * *$ Statistically significant at level $0.01, * * *$ Statistically significant at level 0.001 . 
Table 2. Statistical values of observational variables after structural adjustment

\begin{tabular}{|c|c|c|c|c|c|c|}
\hline Variable & $\begin{array}{l}\text { Estimate } \\
\text { Standard }\end{array}$ & Unstandard & $\mathrm{R}^{2}$ & variance & C.R. & $\mathrm{P}$ \\
\hline \multicolumn{7}{|c|}{ Market Needs } \\
\hline MN5 & 0.32 & 1.00 & 0.10 & 0.72 & - & $* * *$ \\
\hline MN8 & 0.35 & 0.75 & 0.12 & 0.31 & 4.928 & $* * *$ \\
\hline MN13 & 0.59 & 1.61 & 0.35 & 0.39 & 5.940 & $* * *$ \\
\hline MN15 & 0.58 & 1.39 & 0.33 & 0.30 & 5.914 & $* * *$ \\
\hline MN17 & 0.54 & 1.34 & 0.29 & 0.35 & 5.792 & $* * *$ \\
\hline \multicolumn{7}{|c|}{ Business Strategy } \\
\hline BS7 & 0.59 & 1.00 & 0.35 & 0.31 & - & $* * *$ \\
\hline BS8 & 0.56 & 1.05 & 0.32 & 0.39 & 9.57 & $* * *$ \\
\hline BS9 & 0.65 & 1.15 & 0.43 & 0.29 & 10.55 & $* * *$ \\
\hline BS17 & 0.51 & 0.98 & 0.26 & 0.45 & 8.90 & $* * *$ \\
\hline $\mathrm{BS} 20$ & 0.46 & 0.73 & 0.21 & 0.34 & 8.16 & $* * *$ \\
\hline \multicolumn{7}{|c|}{ Research \& Development } \\
\hline RD2 & 0.34 & 1.00 & 0.12 & 0.32 & - & $* * *$ \\
\hline RD3 & 0.50 & 1.71 & 0.25 & 0.38 & 6.198 & $* * *$ \\
\hline RD8 & 0.59 & 2.11 & 0.34 & 0.36 & 6.545 & $* * *$ \\
\hline RD10 & 0.54 & 1.76 & 0.29 & 0.33 & 6.358 & $* * *$ \\
\hline RD11 & 0.48 & 1.51 & 0.23 & 0.32 & 6.124 & $* * *$ \\
\hline RD16 & 0.50 & 1.67 & 0.25 & 0.36 & 6.209 & $* * *$ \\
\hline \multicolumn{7}{|c|}{ Innovation \& Technology } \\
\hline IT5 & 0.50 & 1.00 & 0.25 & 0.44 & - & $* * *$ \\
\hline IT9 & 0.45 & 0.77 & 0.20 & 0.35 & 7.702 & $* * *$ \\
\hline IT14 & 0.47 & 0.67 & 0.22 & 0.23 & 7.991 & $* * *$ \\
\hline IT19 & 0.49 & 0.87 & 0.24 & 0.34 & 8.229 & $* * *$ \\
\hline \multicolumn{7}{|c|}{ Goal Driven Design } \\
\hline GD10 & 0.61 & 1.00 & 0.37 & 0.39 & - & $* * *$ \\
\hline GD12 & 0.61 & 0.97 & 0.37 & 0.37 & 10.493 & $* * *$ \\
\hline GD15 & 0.52 & 0.79 & 0.27 & 0.40 & 9.295 & $* * *$ \\
\hline GD21 & 0.48 & 0.64 & 0.24 & 0.30 & 8.834 & $* * *$ \\
\hline GD22 & 0.48 & 0.68 & 0.23 & 0.36 & 8.704 & $* * *$ \\
\hline
\end{tabular}

* Statistically significant at level $0.05, * *$ Statistically significant at level $0.01, * * *$ Statistically significant at level 0.001 .

From Figure 2 and Table 2, the results of the analysis of the structure of product design management of small and medium industries in Thailand to the international market. The most important statistical values were Factor Loading in both the standardized estimate mode and the unstandardized estimate mode of the observational variables, which can be described as follows

- Observational variables access to consumer data is to obtain valuable information in design (MN5) directly influences market demand variables (Market Needs) statistically significant at the level of 0.001 with a weight of 0.32 .

- Observational variables to analyze consumer demand with a marketing tool to keep it fresh (MN8) directly 
influences market demand latent variables (Market Needs) significantly at the level of 0.001 with a weight of 0.35 .

- Observational variables. The satisfaction survey of the products and services to be used in the design (MN13) directly influence the latent variables of market demand (Market Needs) statistically at the level of 0.001 with a weight of 0.59 .

- Observational variables to create shared value (Co-Creation) among stakeholders within the market (MN15) directly influenced the latent variables of market demand (Market Needs) statistically at the level 0.001 with a weight of 0.58 .

- Observational variables designing products to be marketable with the environmentally-conscious concept (MN17) directly influencing the market needs variables statistically significant at the level of 0.001 with a weight of 0.54 .

- Observational variables to branding to convey product identity and be recognized by consumers (BS7) directly influences the latent variables of the organization's strategy (Business Strategy) statistically at the level of 0.001 with a weight of 0.59 .

- Observational variables to create product images with unified marketing communication (BS8) directly influence the latent variables of the organization's strategy (Business Strategy) at the level 0.001 with a weight of 0.56 .

- Observational variables to plan marketing according to future trends and set clear goals (BS9) directly influence the latent variables of the organization's strategy (Business Strategy) statistically at the level of 0.001 with a weight of 0.65 .

- Observational variables to establish a product design development budget (BS17) directly influencing the latent variables of the organization's strategy (Business Strategy) at a level of 0.001 with a weight of 0.51 .

- Observational variables to promote design skills and competence in organizations (BS20) directly influence the latent variables of the organization strategy (Business Strategy) statistically significant at the level of 0.001 with a weight of 0.46 .

- Observational variables to create a prototype product from research and development results for market testing (RD2) directly influencing the latent variable research \& development (Research \& Development) at the level of 0.001 with a weight of 0.34 .

- Observational variables using the concept of research gap in product design (RD3) directly influences the latent variables research \& development (Research \& Development) statistically at the level 0.001 with a weight of 0.50 .

- Observational variables research and development of products to have constructive differentiation (RD8) directly influences research and development latent variables (Research \& Development) were statistically significant at the 0.001 level with a weight of 0.59 .

- Observational variables there is a modern laboratory for use in the prototype product (RD10) to directly influence the research and development of latent variables statistically at the 0.001 level with a weight of 0.54 .

- Observational variables seeking new raw materials and processes for use in design (RD11) has a statistically significant direct influence on research and development latent variables at the 0.001 level with a weight of 0.48 .

- Observational variables seeking cooperation with education or government agencies that support research and product development (RD16) directly influence the latent variables of research and development (Research and Development) at the level of 0.001 with a weight value. Equal to 0.50

- Observational variables using modern technology in innovative design (IT5) directly influence innovation and technology latent variables statistically at the level of 0.001 with a weight of 0.50 .

- Observational variables exchange technology and innovations with designers (IT9) has a statistically significant direct influence on innovation and technology latent variables at the level of 0.001 with a weight of 0.45 .

- Observational variables having modern and high-speed information technology for storing, communicating, 
and retrieving data (IT14) directly influencing the latent variables, innovation, and technology (Innovation and Technology) at the level of 0.001 with a weight of 0.47 .

- The observational variables were used to create an innovative new generation of hardware and software (IT19) to directly influence the innovation and technology latent variables (Innovation and Technology) at a level of 0.001 with a weight of 0.001. 0.49.

- Observational variables design the content (content) and the story (GD10) according to the identity of the product. There was a statistically significant direct influence on the goal-driven design latent variables at the 0.001 level with a weight of 0.61 .

- Observational variables Creating Shared Value (CSV) between product and social value (GD12) directly influenced the target-driven design latent variables statistically at the 0.001 level with a weight of 0.61 .

- Observational variables pay attention to the economic value of the consumer product (GD15), directly influencing the latent variable of Goal-Driven Design at the level of 0.001 . Equal to 0.52

- Observational variables product design responsive target audience based on process capability (GD21) directly influenced the target-driven design latent variable statistically at the 0.001 scales with a weight of 0.48 .

- Observational variables designing products to be able to protect intellectual property internationally (GD22) has a statistically significant direct influence on the goal-driven design latent variables at 0.001 with a weight of 0.48 .

\section{Discussion}

The market needs directly influence the strategy of the organization (Business Strategy) following the assumptions made. In line with the Panda and Rath (2018) study, it has studied information technology administration strategies in line with organizational agility in a developing country perspective. The study results showed that Information technology management strategies have a direct influence on the agility of an organization's marketing. This was statistically significant at 0.001 and the Rahman and Mannan (2018) study examined the electronic shopping behavior of customers purchasing locally produced fashion apparel. Word of mouth marketing brand recognition and creating a good customer experience. The study results showed that the consumption of information influences word-of-mouth marketing. Brand recognition and creating a good customer experience.

The market needs directly influence research and development latent variables are based on the hypotheses. In line with the Kamboj and Rahman (2017) study, marketing direction was studied. The marketability and the sustainability of innovation: the role of sustainability between consumption and competitive advantage. The study results showed that marketing direction has a direct influence on product development. Statistically significant at level 0.01 (Factor Loading $=0.28$ ).

Business strategy directly influences innovation and technology latent variables according to the assumptions made. In line with the Aghajari and Senin (2014) study, strategic innovation ability can make a difference in both the marketing and management. The strategy of the entrepreneur influences the management of the organization. And the Fornoni et al. (2012) study looked at the impact of social costs of entrepreneurship on performance. Case studies of access to information in Argentina. The study results showed that social costs entrepreneurs influence work efficiency.

Research and development latent variables directly influence innovation and technology latent variables according to the hypotheses. In line with Cui and $\mathrm{Wu}$ (2015) studies on product development through innovation to achieve production efficiency through the cooperation of customers. Which the research results showed research and development influences customer engagement in creating new product innovations (Ruiz-Jimenez and Fuentes-Fuentes, 2013). Knowledge-gathering, innovation, organizational performance incorporate technology (Dostál et.al., 2017). The study results showed that the ability to integrate research and development knowledge influences product innovation and process innovation.

\section{Conclusion}

An analysis of the relationship between structural variables, product design management, of medium and small industries in Thailand to the international market, found that the relationship between structural variables. Statistically significant dual latent variables at the level of 0.001, namely Market Needs directly influence the corporate strategy latent variables (Business Strategy) market needs influence. To direct research and development latent variables business strategy direct influence on innovation and technology latent variable and research and 
development latent variable. The latent variables were related to innovation and technology, while the latent variables that were statistically significant at the level of 0.01 were the research and development latent variables. Goal-Driven Design and latent variables with statistical significance of the paired variable at 0.05 , namely innovation and technology, directly influences the target design latent variables. Also, the analysis of the relationship between the latent and observational variables found that the relationship between the structural variables. All variables were statistically significant at the 0.001 level.

From the research of product design management structure of small and medium industries in Thailand to the international market. The researcher recommends the findings of the research as a guideline for business development focusing on creative product design and it is in demand among consumers. Also, the results of the research indicate the creation of new knowledge for academics in the university. To focus on product design to make it attractive to consumers.

From the research of the product design management structure of medium and small industries in Thailand to the international market. That the researcher has already presented. There is still a need to develop a structure for use in real organizations. To apply to the organizational context following the resulting structure. To get the most benefits for use. Once it is implemented, it is necessary to develop structured modifications that are specific to that organization to create an organizational design management strategy that is different from the competition in the market. To create a competitive advantage and sustainable business growth in the international market education.

\section{References}

Aghajari, N., \& Senin, A. A. (2014). Strategic orientation and dual innovative operation strategies. Asia-Pacific Journal of Business Administration, 6(2), 127-147. https://doi.org/10.1108/APJBA-07-2013-0075

Alvesson, M. (2001). Knowledge work: Ambiguity, image and identity. Human relations, 54(7), 863-886. https://doi.org/10.1177/0018726701547004

Arbuckle, J. L. (2011). IBM® SPSS® AmosTM 20 User 'Guide. Mount Pleasant: Amos Development Corporation.

Barney, J. B. (2012) Purchasing, supply chain management and sustained competitive advantage: The relevance of resource-based theory. Journal of Supply Chain Management, 48(2), 3-6. https://doi.org/10.1111/ j.1745-493X.2012.03265.x

Comrey, A., \& Lee, H. (2002). A first course in factor analysis. Hillsdale, New Jersey: Erlbaum.

Cui, A. S., \& Wu, F. (2016). Utilizing customer knowledge in innovation: antecedents and impact of customer involvement on new product performance. Journal of the Academy of Marketing Science, 44(4), 516-538. https://doi.org/10.1007/s11747-015-0433-x

Dostál, J., Wang, X., Steingartner, W., \& Nuangchalerm, P. (2017). Digital intelligence-new concept in context of future school of education. In Proceedings of ICERI2017 Conference 16th-18th November 2017. https://doi.org/10.21125/iceri.2017.0997

Fornoni, M., Arribas, I., \& Vila, J. E. (2012). An entrepreneur's social capital and performance: The role of access to information in the Argentinean case. Journal of Organizational Change Management, 25(5), 682-698. https://doi.org/10.1108/09534811211254572

Gilbert R., Loxley D., Tomley S., \& Walisiewicz, M. (2014). The business book. London. Dorling Kindersley Limited.

Kamboj, S., \& Rahman, Z. (2017). Market orientation, marketing capabilities and sustainable innovation: The mediating role of sustainable consumption and competitive advantage: Management Research Review, 40(6), 698-724. https://doi.org/10.1108/MRR-09-2014-0225

Kotler, P., \& Armstrong, G. (2013). Principles of marketing. $15^{\text {th }}$ ed. Englewood: Prentice - Hall.

Naiman, L. (2018). Design Thinking as a Strategy for Innovation. Retrieve (January 31, 2018). Available from https://www.creativityatwork.com/design-thinking-strategy-for-innovation.

National Institute of Development Administration, Institute. (2011). Final report on strategic development strategy for creative economy in fashion industry 2011. Bangkok: National Institute of Development Administration, Academic Service Center.

Office of Small and Medium Enterprises Promotion. (2019). Situation report small and medium enterprises in 2018. Bangkok: Office of Small and Medium Enterprises Promotion. 
Panda, S., \& d Rath, K. S. (2018). Strategic IT-business alignment and organizational agility from a developing country perspective. Journal of Asia Business Studies, 12(4), 422-440. https://doi.org/10.1108/ JABS-10-2016-0132

Rahman, S. M., \& Mannan, M. (2018). Consumer online purchase behavior of local fashion clothing brands: Information adoption, e-WOM, online brand familiarity and online brand experience. Journal of Fashion Marketing and Management: An International Journal, 22(3), 404-419. https://doi.org/10.1108/ JFMM-11-2017-0118

Ruiz-Jimenez, M. J., \& Fuentes-Fuentes, M. M. (2013). Knowledge combination, innovation, organizational performance in technology firms. Industrial Management \& Data Systems, 113(4), 523-540. https://doi.org/ $10.1108 / 02635571311322775$

Sripaiphan, C. (2010). Development guidelines for upgrading OEM business to ODM and OBM. Development guidelines for upgrading OEM business to ODM and OBM. [Online Journal] (Accessed November 1, 2018). From https: / /tmec.nectec.or.th/public/uploaded/Seminar/SubCon2010/Oem_odm_obm.pdf

Valaei, N., Rezaei, S., \& Emami, M. (2017). Explorative learning strategy and its impact on creativity and innovation: An empirical investigation among ICT-SMEs. Business Process Management Journal, 23(5), 957-983. https://doi.org/10.1108/BPMJ-12-2015-0179

\section{Copyrights}

Copyright for this article is retained by the author(s), with first publication rights granted to the journal.

This is an open-access article distributed under the terms and conditions of the Creative Commons Attribution license (http://creativecommons.org/licenses/by/4.0/). 